GU J Sci, Part C, 6(3): 715-720 (2018)

Gazi Üniversitesi
Fen Bilimleri Dergisi
PART C: TASARIM VE TEKNOLOJI
dergipark.gov.tr/http-gujsc-gazi-edu-tr

\title{
Makale Başlığı Karbon Kaplı Nano-Bor Kullanılarak Hazırlanan Süperiletken MgB2 Numunelerde Magnezyum Kaynağının Yapısal ve Elektriksel Özellikler Üzerindeki Rolü
}

\author{
Serap SAFRAN ${ }^{1,2}$ \\ ${ }^{I}$ Ankara Üniversitesi, Fen Fakültesi, Fizik Bölümü, 06100, Tandoğan/ANKARA \\ ${ }^{2}$ Ankara Üniversitesi, Süperiletken Teknolojileri Uygulama ve Araştırma Merkezi, 50. Yıl Kampüsü, Gölbaşı/ANKARA
}

\begin{abstract}
Öz
Makale Bilgisi

Bașvuru: 16/04/2018

Düzeltme: 09/05/2018

Kabul: 29/05/2018

Anahtar Kelimeler

Süperiletken $\mathrm{MgB}_{2}$ numuneler üzerinde magnezyum kaynağının yapısal ve elektriksel özellikler üzerine etkisi detaylı olarak çalışılmıştır. Numuneler geleneksel bir metot olarak bilenen katıhal reaksiyonu yöntemiyle iki farklı magnezyum kaynağı kullanılarak hazırlanmıştır. Bor kaynağı olarak yüksek saflıkta bor yerine \% 2,3 karbon kaplı nano-bor tercih edilmiştir. Üretilen numuneler X-Işını kırınımı (XRD), taramalı elektron mikroskobu (SEM), elektron dağılımlı spektroskopi (EDS) ve özdirence karşılık sıcaklık $(\rho-\mathrm{T})$ ölçümleri ile karakterize edilmiştir. Bu çalışmada, magnezyum kaynağının külçe numunelerin elektriksel özelliklerini üzerinde etkisini araştırmak için elektriksel özellikler ölçümler üzerinde yoğunlaşılmıştır. Hazırlanan numunelerin kritik süperiletken geçiş sıcaklığı, tane boyutu, fazların saflığı, yüzey morfolojisi ve özdirenç değerleri birbirleri ile karşılaştırılmıştır.
\end{abstract}

$\mathrm{MgB}_{2}$

Karbon kaplı nanobor

Magnezyum kaynağ

Süperiletken özellikler

Keywords

$M g B 2$

Carbon encapsulated

nanoboron

Magnesium source

Superconducting

properties

\section{Role of Magnesium Source on Structural and Superconducting Properties of $\mathrm{MgB}_{2}$ Using Encapsulated Nano Boron}

\section{GIRIŞ (INTRODUCTION)}

2001 yılında süperiletken olduğu keşfedilen $\mathrm{MgB}_{2}$, ikili bileşikler arasında yaklaşık $39 \mathrm{~K}$ 'lik yüksek geçiş sıcaklığı ile dikkati çekmektedir[1]. Bu malzeme, geleneksel metalik süperiletkenlerle kıyaslandığ1 zaman, modern kryo-soğutma sistemlerinin kullanımına olanak vermesi sebebiyle çok ideal ve ekonomik hale gelmektedir. Basit kristal yapısı, düşük anizotropi sergilemesi, zayıf bağ probleminin olmaması vb. etkenler bu malzemenin büyük ölçekli uygulamalarda kullanılabilmesine imkan sağladığı için son yıllarda üzerinde yoğun olarak çalışmalar devam etmektedir. Süperiletkenlik parametrelerini geliştirebilmek amacıyla üretim teknikleri, katkılama, ekleme vb. birçok yöntem kullanılmaktadır [2]. 
Başlangıç tozu olarak kullanılan bor elementinin safsızlı̆̆ının süperiletkenlik özellikleri üzerinde etkisi yaygın olarak çalışılmıştır [3,4]. Bor elementinin saflığının arttırılması ile daha az safsızlık fazlarının oluştuğu, süperiletken geçiş sıcaklığının değiştiği ve kritik akım taşıma kapasitesini arttırıldığı belirlenmiştir [3, 4]. Bunu yanı sıra, MgB2'nin süperiletkenlik özelliklerini iyileştirmek için genel olarak yapısında karbon elementi bulunan katkılamalar ve magnezyum kaynağ1 olarak $\mathrm{Mg}$ yerine $\mathrm{MgH} 2$ kullanılması üzerine de çalışmalar bulunmaktadır. Bunlara örnek olarak silisyum karbür (SiC) [5], B4C [6], karbon (C) [7], karbon nanotüp(CNT) [8], karbohidratlar [9, 10] ve aromatik hidrokarbonlar [11] verilebilir. Karbon ile bor periyodik cetvelde peş peşe gelen, atom numaraları arasında bir fark bulunan elementlerdir. $\mathrm{Bu}$ sebeple $\mathrm{B}$ ile $\mathrm{C}$ yapıda yer değiştirerek daha yüksek akım taşıma kapasitesine ulaşılmasını sağlayabilmektedirler. Yapı içinde meydana gelen bu değişiklik perçinlenme merkezlerinin oluşmasını ve kritik akım yoğunluğunun arttırılmasını sağlamaktadır. Ancak yapılacak olan bu eklemenin belirli bir oranda olması gerekmektedir. Optimum değerin üzerinde yapılan eklemeler yapıyı bozmakta ve süperiletkenlik parametrelerini düşürmektedir. Bu sebeplerle, bu çalışmada bor kaynağı olarak saf bor yerine karbon ile kaplanmış nano-bor kullanmış ve iki farklı magnezyum kaynağının süperiletken MgB2 külçe numunelerin yapısal ve elektriksel özeliklerini nasıl etkilediği araştırılmıştır. Ayrıca 1sıl işlem sıcaklığının etkisinin ne olduğu anlaşılmaya çalışılmıştır.

\section{MALZEME HAZIRLAMA VE YÖNTEM (SAMPLE PREPARATION AND METHOD)}

$\mathrm{MgB}_{2}$ külçe numuneler iki farklı magnezyum kaynağ $\left(\mathrm{Mg}, \%\right.$ 99,9 ve $\mathrm{MgH}_{2}, \%$ 96,5) ve \% 98 saflıkta, yaklaşık olarak \% 2,3 karbon içeren, karbon kaplı nano-bor (CENB) (Pavezyum Kimya, Türkiye) kullanılarak üretilmiştir. CENB'nin üretim prosedürü [12]'da detaylı olarak anlatılmaktadır. Başlangıç tozuna, düşük erime sıcaklığına sahip olan magnezyumun, 1sıl işlem sırasındaki buharlaşmasını kompanse etmek için ağırlıkça \% 10 fazla magnezyum eklenmiştir. Magnezyum kaynağının etkisini belirlemek için iki grup halinde farklı tavlama sıcaklıklarında toplam olarak altı külçe numune hazırlanmıştır. MgB2 külçe numunelerin hazırlama yöntemi [3] detaylı olarak verilmektedir. Final tozu $400 \mathrm{MPa}$ basınç altında $13 \mathrm{~mm}$ çap olacak şekilde basılarak külçe haline getirilmiştir. Her numune ayrı ayrı tantalyum folyo ile sarılarak paslanmaz çelik boru içinde $750{ }^{\circ} \mathrm{C}, 800{ }^{\circ} \mathrm{C}$ ve $850{ }^{\circ} \mathrm{C}$ 'de 1 saat yüksek saflıkta argon $(\% 99,99)$ atmosferinde 10 bar basınç altında tüp fırında 1sıl işleme tabi tutulmuştur. Fırın, 1sıtma hızı $5{ }^{\circ} \mathrm{C} / \mathrm{dak}$ seçilmiş olup numuneler 1 sıl işlem tamamlandıktan sonar firın içinde oda sıcaklığına gelene kadar soğutulmuştur. Hazırlanan numuneler M750, M800, M850 and MH750, MH800, MH850 şeklinde adlandırılmıştır. Harf sembolü kullanılan magnezyum kaynağını ( $\mathrm{M}$ sembolü $\mathrm{Mg}, \mathrm{MH}$ sembolü $\mathrm{MgH}_{2}$ ), sayı değeri ise 1 sıl işlem sıcaklığını temsil etmektedir. Sonuç olarak M serisi ve MH serisi olmak üzere iki grup numune üretilmiştir.

Fazları belirlemek ve yapı hakkında bilgi edinmek için toz X-1şınları kırınımı desenleri Rigaku D/MaxIIIC difraktometre ile $\mathrm{CuK} \alpha$ radyasyonu kullanılarak alınmıştır. Veriler oda sıcaklığında $2 \theta=10^{\circ}-60^{\circ}$ olacak şekilde 3\% dak tarama hızında alınmıştır. Numunelerin yüzey morfolojileri $20 \mathrm{kV}$ 'da 15,000 büyütme yapılarak FEI Quanta FEG 250 cihazı ile gözlemlenmiştir. Elektriksel özdirence karşı sıcaklık grafikleri 10-200 K sıcaklık aralığında standart dört nokta kontak yöntemi kullanılarak Janis CCS-450 marka kapalı devre kryostat kullanılarak alınmıştır.

\section{TARTIŞMA (DISCUSSION)}

Farklı magnezyum kaynağı kullanarak üretilen numuneler ait XRD desenleri Şekil 1.a ve 1.b'de gösterilmektedir. Ana pikin $\mathrm{MgB}_{2}$ fazına ait olduğu görülmekle birlikte, $\mathrm{Mg}$ fazına ait piklerde belirlenmiştir. Reaksiyona girmemiş $\mathrm{Mg}$ piklerinin görülme sebebinin, numune hazırlaması sırasında başlangıçta eklenen fazla Mg'den kaynaklandığı düşünülmektedir. Buna ek olarak sadece M750 numunesinde $\mathrm{MgO}$ pikine rastlanmıştır. $\mathrm{MgO}$ pikinin görülmesi, yetersiz ısıl işlem sıcaklığ hazırlama sırasında presleme işlemi yaparken numune için tuzaklanan ve/veya numunenin oksitlenmemesi için sarılan tantalyum folyo içinde kalan havadan kaynaklanabileceği şeklinde yorumlanmıştır. $\mathrm{MgB}_{2}$ 'ye ait ana (101) pikinin genişliği, $\mathrm{M}$ serisi numunelerde artan 1sıl işlem sıcaklığı ile artarken, aynı koşullar altında hazırlanmış MH serisi numunelerde azalmaktadır. Pik genişliği ile tane boyutu arasında sıkı bir ilişki bulunmaktadır. Pikin genişliğinin artması Debye-Sherrer eşitliğine göre tane boyutunun azalması anlamına gelmektedir. Debye-Sherrer formülü ortalama tane boyutu hesaplamak için kullanmaktadır [13], tane boyutu D; 


$$
D=\frac{0.941 \lambda}{\beta \cos \theta}
$$

şeklinde verilir. Burada $\lambda$, $\beta$, and $\theta$ sırasıyla kullanılan X-1şınının dalgaboyu (15,418 nm), ana pikin maksimumunun yarı genişliği (FWHM) ve Bragg kırınım açısı olarak tanımlanmıştır. Pik genişliğinde görülen bu davranışa göre, 1sıl işlem sıcaklığının artması ile $M$ serisi numunelerde tane boyutunun geliştirirken, MH serisi numunelerde düşürdüğü sonucuna ulaşabilmektedir.
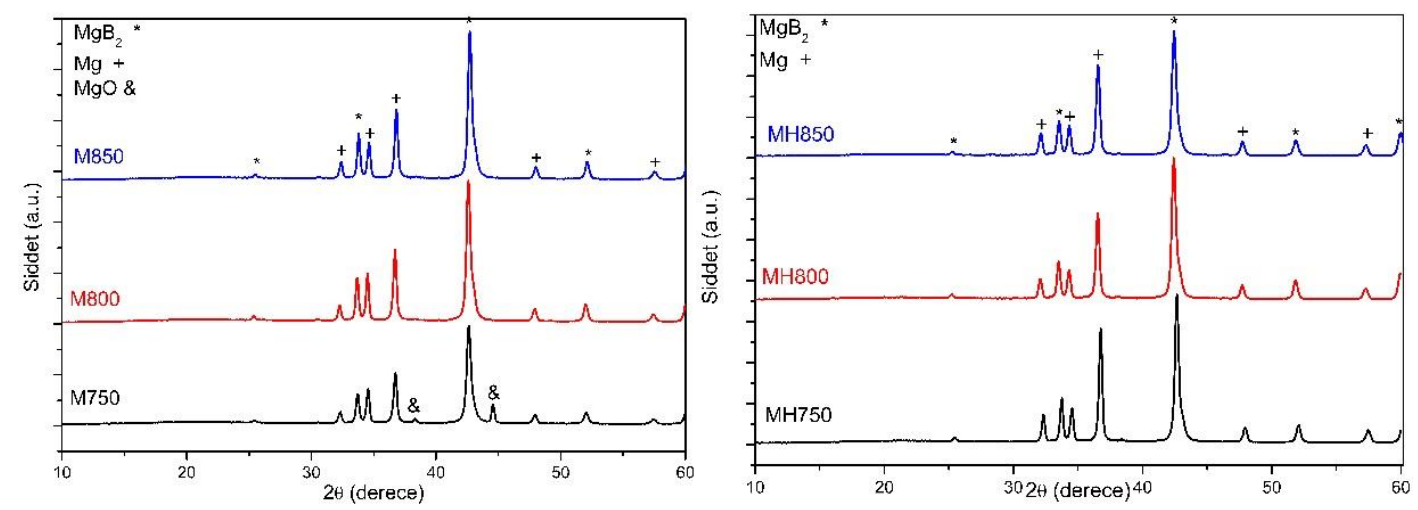

Şekil 1. a) M serisi ve b) MH serisi numunelere ait XRD grafikleri.

Hazırlanan bütün külçe numunelere ait 15.000 büyütme altında çekilmiş olan SEM fotoğrafları Şekil 2'de verilmektedir. Şekil 2'den de açıkça görüldüğü üzere numune yüzeyinde farklı şekil ve boyutta oldukça fazla sayıda boşluk bulunmaktadır. Bu gözenekli yapı $\mathrm{MgB}_{2}$ numunelerde çözümlenmesi gereken ana problemlerden biri olarak karşımıza çıkmaktadır. Bu problemi çözmek için numune hazırlanması sırasında birçok yöntem uygulanmıştır. Numuneye katkı yapma, farklı bor kaynakları kullanmak, 1sıl işlem sıcaklığını optimize etmek bunlardan birkaçıdır. [4, 14, 15]. SEM fotoğraflarından numune boyutunu tam olarak tespit etmek oldukça güçtür. Ancak bu mikro grafiklerden tane boyutu hakkında genel bir fikir edinmek mümkündür. $\mathrm{MgB}_{2}$ 'nin ana yapısının çubuk benzeri tanelerden meydana geldiği belirlenmiştir. Isıl işlem sıcaklığının artması ile $\mathrm{M}$ serisi numunelerde tane boyutunun büyüdüğü, $\mathrm{MH}$ serisi numunelerde ise küçüldüğü mikro yapıdan açıkça görülmektedir. Elde edilen bu sonuçlar XRD sonuçları ile tam bir uyum içerisindedir.
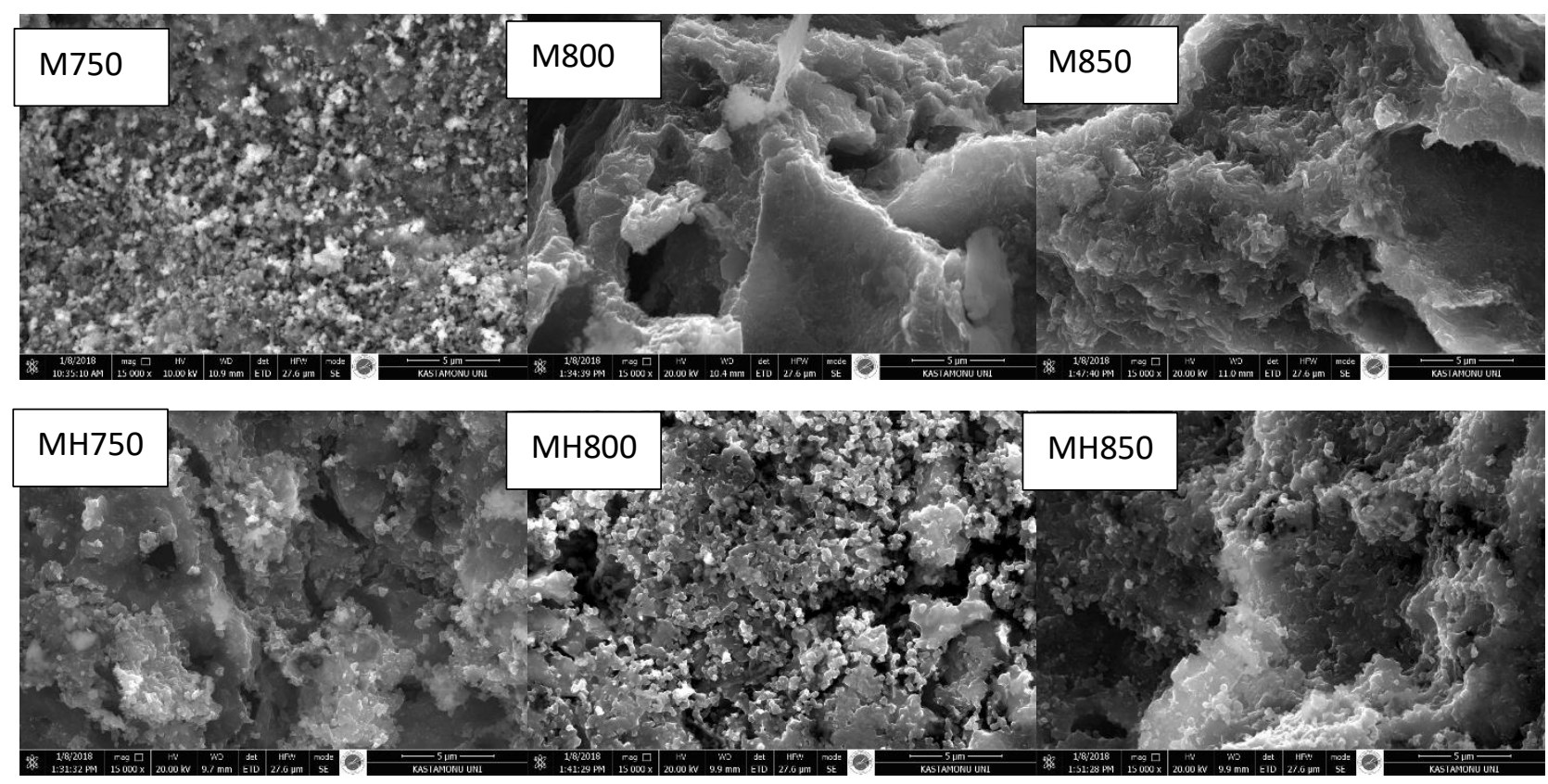

Şekil 2. Hazırlanan külçe numunelere ait 15.000 büyütme altında çekilmiş olan SEM fotoğrafları. 
Numunelerin EDS analizi sonucunda elde edilen elemental yüzdeleri Tablo 1'de verilmektedir. MH serisi numunelerde $\mathrm{B}$ bileşiğinin elemental oranı azalırken, $\mathrm{Mg}$ elementinin oranı azalmaktadır. $\mathrm{M}$ serisi numunelerde ise, 1 sıl ișlem süresi $750{ }^{\circ} \mathrm{C}$ ' den, $800{ }^{\circ} \mathrm{C}$ ve $850{ }^{\circ} \mathrm{C}$ çıkarıldığında B bileșiğinin elemental oranı azalmış, $\mathrm{Mg}$ elementinin oranı ise artmıştır, ancak bu değişimler sistematik değildir. Bütün numuneler içinde $\mathrm{O}$ elementinin elemental oranı M750 numunesinde en küçük bulunmuştur. Bu sonuç, sadece M750 numunesinde $\mathrm{MgO}$ piklerinin bulunmasını açıklamaktadır.

Tablo 1. Hazırlanan külçe numunelerin EDS analizi sonucunda bulunan elementel yüzdeleri

\begin{tabular}{cccc}
\hline Numune adı & B & O & Mg \\
& \% wt & \% wt & \% wt \\
\hline M750 & 50,21 & 2,88 & 46,72 \\
M800 & 42,59 & 6,25 & 51,16 \\
M850 & 42,92 & 7,09 & 49,99 \\
MH750 & 43,35 & 4,21 & 52,44 \\
MH800 & 46,40 & 4,78 & 48,83 \\
MH850 & 47,60 & 5,05 & 47,60 \\
\hline
\end{tabular}

Sıfır manyetik alan altında özdirencin sıcaklığa bağımlılık grafiği $(\rho-T)$ Şekil 3'te gösterilmiştir. Bütün numuneler süperiletkenlik geçiş sıcaklığının üstünde metalik davranış göstermektedir. $\rho-T$ grafiğinden yararlanılarak bulunan süperiletkenliğe geçiş sıcaklıkları Tablo 2 'de verilmektedir. Lineer davranıştan

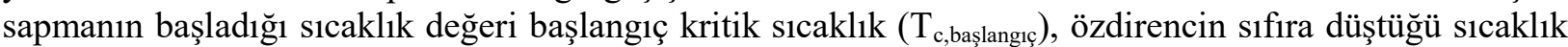
değeri ise denge kritik sıcaklık değeri $\left(\mathrm{T}_{c, \text { bitis }}\right)$ olarak alınmıştır. Tablo 2'de açık bir şekilde görüldüğü üzere $\mathrm{M}$ serisi numunelerin 1sıl işlem sıcaklığından bağımsız olarak kritik sıcaklık değerleri birbirlerine oldukça yakındır, bu seride en keskin süperiletkenlik geçișin M850 numunesinde olduğu belirlenmiștir. Çünkü MH850 numunesinin süperiletkenlik geçişi $(\Delta \mathrm{T})$ 0,9 $\mathrm{K}$ gibi dar bir sıcaklık aralığında gerçekleşmiştir. Isıl işlem sıcaklığı arttıkça süperiletkenlik geçişinin keskinleştiği $(\Delta \mathrm{T}$ değerlerinin azalması) Tablo 2'den değerlendirilebilir. M serisi numuneler için belirlenen kritik sıcaklık değerleri literatür ile de uyum içindedir [17]. MH serisi numunelerde ise 1 sıl işlem sıcaklığı arttıkça $T_{\text {c.bașlangıc }}$ değerinin 28,5 K'den 35,4 K'ye arttığı gözlenmiştir, benzer davranış $\mathrm{T}_{\mathrm{c}, \mathrm{bitiş}}$ değerinde de görülmektedir. MH serisi numunelerde de 1 sıl işlem sıcaklığ $1850{ }^{\circ} \mathrm{C}$ çıkarıldığında geçişin oldukça keskin olduğu saptanmıştır. Isıl işlem sıcaklı̆̆ının artırılması ile süperiletkenlik geçişin keskin olması taneler arası bağlantının iyi kurulduğu şeklinde yorumlanabilir. Magnezyum kaynağı olarak $\mathrm{MgH}_{2}$ kullanılan numunelerin kritik sıcaklık değerleri, Mg kullanılarak hazırlanan numunelere göre daha yüksek ve süperiletken geçiş genel olarak daha keskindir. Ancak her iki seri numunede elde edilen kritik sicaklik değerleri, literatür de $\mathrm{MgB}_{2}$ için verilen yaklaşık $39 \mathrm{~K}$ 'lik değerle karşılaştırıldığı zaman daha düşük olduğu görülmektedir[1].

Tablo 2. Hazırlanan numunelerin kritik geçiş sıcakll̆̆g dĕ̆erleri.

\begin{tabular}{cccc}
\hline Numune adi & $\mathbf{T}_{\mathbf{c}, \text { basslangic }}(\mathbf{K})$ & $\mathbf{T}_{\mathbf{c}, \text { bitis }}(\mathbf{K})$ & $\Delta \mathbf{T}(\mathbf{K})$ \\
\hline M750 & 29,1 & 27,0 & 2,1 \\
M800 & 29,3 & 27,0 & 2,3 \\
M850 & 28,9 & 27,8 & 1,1 \\
MH750 & 28,5 & 25,6 & 2,9 \\
MH800 & 33,9 & 32,9 & 1,0 \\
MH850 & 35,4 & 34,5 & 0,9 \\
\hline
\end{tabular}

Süperiletken numunelere katkılama yapıldığı zaman kritik sıcaklık değerinin düştüğü bilinen bir gerçektir $[13,17]$. Numune üretiminde başlangıç tozu olarak kullanılan bor kaynağı \% 2,3 karbon kaplanmış olması sebebiyle düşük kritik sıcaklık değerlerinin elde edildiği değerlendirilmektedir. Etrafı karbon ile kaplanmış bor elementleri malzemede katkı yapılmış etkisi yaratmış olduğu düşünülmektedir. 

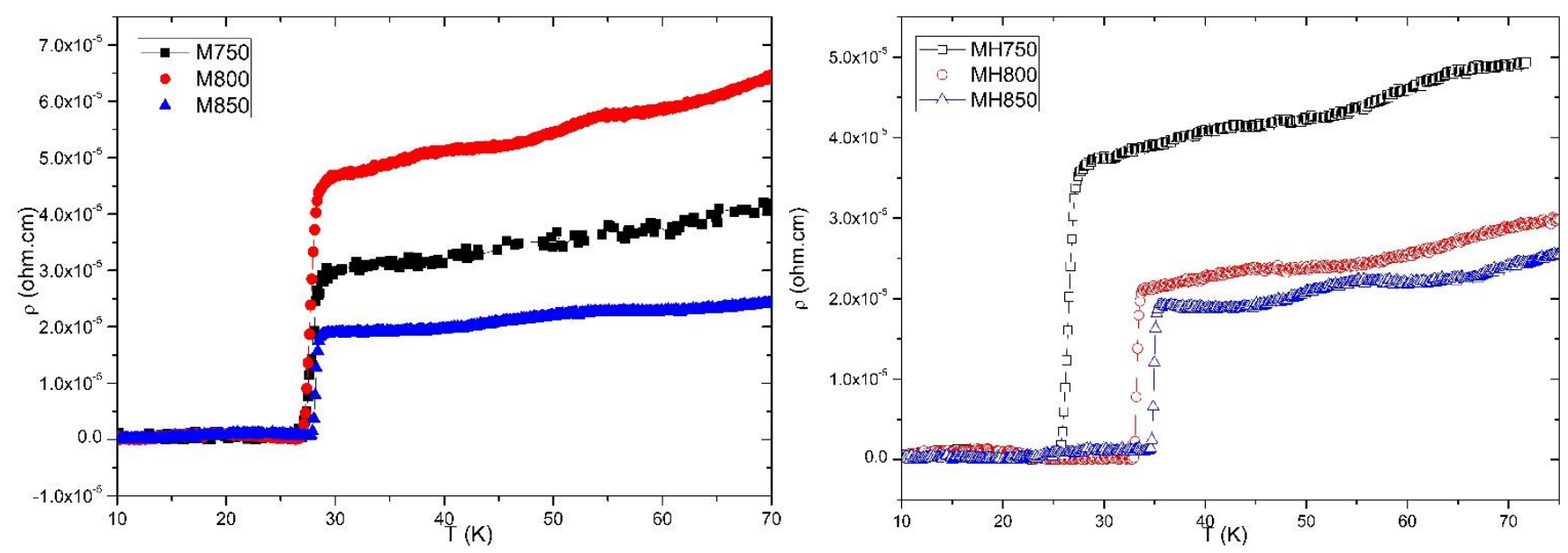

Şekil 3. Sifır manyetik alan altında özdirencin sıcaklı̆̆a bă̆ımlılık grafiği.

\section{SONUÇ (CONCLUSIONS)}

İki farklı magnezyum kaynağı ve karbon kaplı nano-bor kullanılarak katıhal reaksiyon yöntemi ile iki seri $\mathrm{MgB}_{2}$ külçe numune hazırlanmıştır. Yapısal karakterizasyon için numunelerin XRD, SEM ve EDS ölçümleri alınmıştır. Hazırlanan numunelerde ana fazın $\mathrm{MgB}_{2}$ olduğu tespit edilmiş olup, tane büyüklüklerinin $\mathrm{M}$ serisi numuneler için artarken, $\mathrm{MH}$ serisi numuneler için azaldığı belirlenmiştir. SEM ölçümlerinden alınan sonuçlar XRD ölçümlerini doğrulamaktadır. Elektriksel karakterizasyon için numunelerin $\rho$-T ölçümleri alınmış olup, hazırlanmış olan bütün numunelerde süperiletkenliğin oluştuğu tespit edilmiştir. Ayrıca $\rho$-T grafiğinden yararlanılarak süperiletkenlik geçiş sıcaklıkları belirlenmiştir. Bulunan değerler, $\mathrm{MgB}_{2}$ 'nin literatürde kayıt edilen yaklaşık $39 \mathrm{~K}$ 'lik değerinden düşüktür. Bunun sebebinin başlangıç tozu olarak kullanılan bor kaynağının karbon kaplı olmasına bağlı olduğu değerlendirilmiştir.

\section{KAYNAKLAR (REFERENCES)}

[1] J. Nagamatsu, N. Nakagawa, T. Muranaka, Y. Zenitani, J. Akimitsu, Nature 410 (2001) 63. Doi: $10.1038 / 35065039$

[2] Y. Yamada, M. Kanazawa, T. Ohno, K. Tachikawa, K. Kajikawa, T. Inoue, I. Aoki, A. Matsumoto, and H. Kumakura, IEEE Trans Appl Supercond 22 (2012) 3. Doi: 10.1109/TASC.2011.2176295

[3] S. Safran, A. Kılıç, E. Asikuzun, E. Kılıcarslan, O. Ozturk, A. Gencer, J Mater Sci: Mater Electron 25 (2014) 2737. Doi. 10.1007/s10854-015-2733-9

[4] S. Safran, E. Kılıçarslan, A. Kılıç, A. Gencer, Cryogenics 63 (2014) $133 . \quad$ Doi. 10.1016/j.cryogenics.2014.04.001

[5] S.X. Dou, S. Soltanian, J. Horvat, X.L. Wang, S.H. Zhou, M. Ionescu, H.K. Liu, Applied Physics Letters 81 (2002) 18. Doi: 10.1063/1.1517398

[6] P. Lezza, C. Senatore, R. Fl ukiger, Supercond Sci Technol 19 (2006) 1030. Doi:10.1088/09532048/19/10/007

[7] Y. Ma, X. Zhang, G. Nishijima, K. Watanabe, S. Awaji, X. Bai, Appl Phys Lett 88 (2006) 072502. Doi: $10.1063 / 1.2173635$

[8] J. H. Kim, W. K. Yeoh, M. J. Qin, X. Xu, S. X. Dou, P. Munroe, H. Kumakura, T. Nakane, and C. H. Jiang, Appl Phys Lett 89 (2006) 122510. Doi: 10.1063/1.2355467 
[9] M.S.A. Hossain, J.H. Kim, X. Xu, X.L. Wang, M. Rindfleisch, M. Tomsic, M.D. Sumption, E.W. Collings, S.X. Dou, Supercond Sci Technol 20 (2007) L51. Doi:10.1088/0953-2048/20/8/L03

[10] J.H. Kim, S. Zhou, M.S.A. Hossain, A.V. Pan, S.X. Dou, Appl Phys Lett 89 (2006) 142505. Doi: $10.1063 / 1.2358947$

[11] H Yamada, N. Uchiyama, A. Matsumoto, H. Kitaguchi, H. Kumakura, Supercond Sci Technol 20 (2007) L30. Doi:10.1088/0953-2048/20/6/L02

[12] Barua S., Hossain M. S., Al Ma Z., Patel D., Mustapic M., Somer M., Acar S., et al., Scr. Mater., 104 (2015) 37. Doi. 10.1016/j.scriptamat.2015.04.003

[13] P. Debye and P. Scherrer, Phys. Z., 1917, 18, 291.

[14] M. G. Babaoglu, S. Safran, O. Cicek, H. Ag1l, E. Ertekin, Md S. A. Hossain, E. Yanmaz, A. Gencer J Magn Magn Mater 324 (2012) 3455. Doi:10.1016/j.jmmm.2012.02.064

[15] M. Muralidhar, K. Inoue, M. R. Koblischka, M. Tomita, and M. Murakami, J. Alloys Compd., 608 (2014) 102. Doi. 10.1016/j.jallcom.2014.04.017

[16] İ. Duz, S. B. Guner, O. Erdem, I. Demir, V. Kapucu, S. Celik, K. Ozturk, S. Hossain, A. Gencer, Yanmaz, J Supercond Nov Magn 27 (2014) 2241. Doi 10.1007/s10948-014-2602-4

[17] D. Bumin, E. Yanmaz, M. Basoglu, A. Gencer, J Supercond Nov Magn 24 (2011) 211. Doi 10.1007/s10948-010-1048-6 